\title{
Aspergillus niger endocarditis complicating aortic tissue valve replacement
}

\author{
RS MOORE, PS HASLETON, RAM LAWSON, TN STANBRIDGE \\ From the Departments of Cardiothoracic Surgery, Pathology, and Bacteriology, Regional Cardiothoracic \\ Centre, Wythenshawe Hospital, Manchester
}

With the increase in valve replacement over the past 20 years has come the problem of fungal endocarditis. Aspergillus in most series is the second commonest cause of fungal endocarditis ${ }^{12}$ reported on native or mechanical valves and the infection is usually fatal. ${ }^{2}$ Only two cases ${ }^{34}$ have been reported on tissue prostheses. We report the third case of aspergillus infection on a tissue valve and the first on the Xenofic tissue valve.

\section{Case report}

A 63 year old man underwent aortic valve replacement with a Xenofic tissue prosthesis for calcific aortic stenosis and incompetence. Before operation he had had a small varicose ulcer over his right ankle, culture swabs yielding Staphylococcus aureus and Pseudomonas aeruginosa. Surgery was delayed until the ulcer was almost healed. Antibiotic prophylaxis for the operation comprised cloxacillin and netilmicin, commencing with the premedication and continuing for $\mathbf{4 8}$ hours after operation. He made an uneventful recovery and was discharged on the 11 th postoperative day taking nicoumalone.

Fifty three days after operation he was readmitted with a two week history of intermittent orthopnoea, night sweats, and general malaise, heralded by an episode of superficial thrombophlebitis in the right leg. He had started to take oxytetracycline and ampicillin seven days before. He was anaemic, mildly jaundiced, and febrile $\left(38.5^{\circ} \mathrm{C}\right)$, with a sinus tachycardia of 100 beats/min. New aortic systolic and diastolic murmurs were present. Investigations showed the haemoglobin concentration to be $7.7 \mathrm{~g} / \mathrm{dl}(52 \%)$, the white cell count $21 \times 10 \% / 1$, reticulocytes $10 \%$, erythrocyte sedimentation rate $82 \mathrm{~mm}$ in one hour, urea and electrolytes normal, serum bilirubin $30 \mu \mathrm{mol} / 1(1.8 \mathrm{mg} / 100 \mathrm{ml})$, total proteins $6.2 \mathrm{~g} / \mathrm{dl}$, albumin $2.8 \mathrm{~g} / \mathrm{dl}$. Blood cultures were negative on five occasions.

Endocarditis was diagnosed and treatment was started with netilmicin and flucloxacillin. His condition worsened and three days later he suffered a cerebrovascular accident causing a left hemiparesis. He died four days later.

Necropsy showed varicose eczema on both legs and a small ulcer on the right ankle; there were no splinter

Address for reprint requests: Dr RS Moore, Warrington General Hospital, Warrington, Cheshire WA5 1QG.

Accepted 12 September 1983

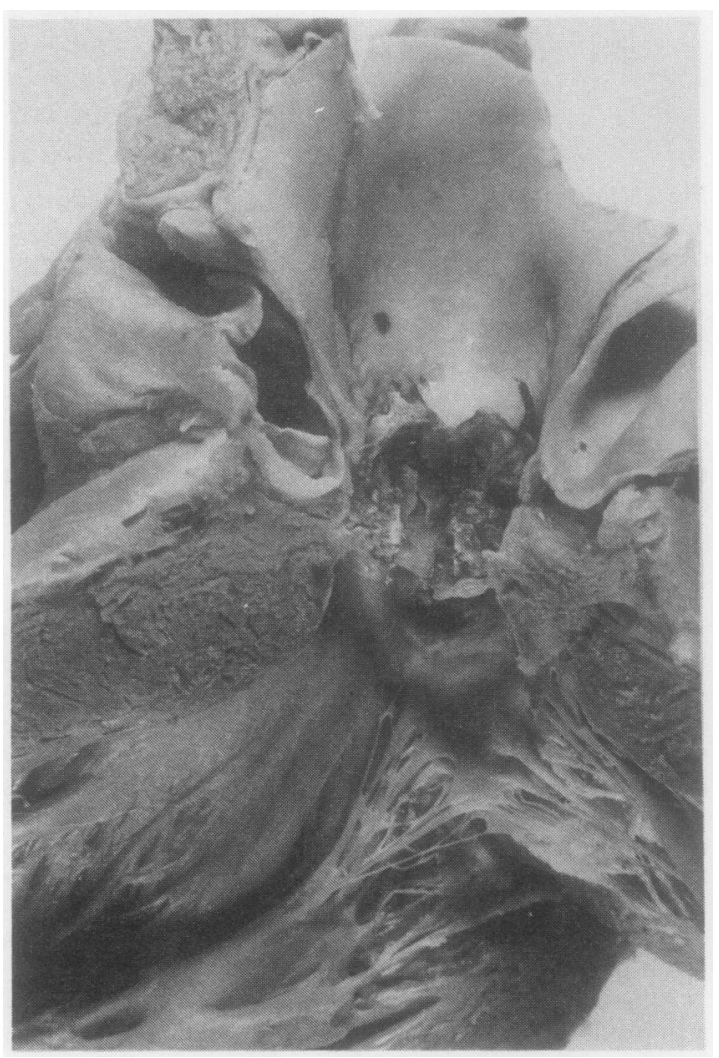

Fig 1 Postmortem specimen showing prosthetic aortic valve coated with red, friable thrombus.

haemorrhages. The heart was enlarged, weighing $630 \mathrm{~g}$. The right atrium was dilated, as was the tricuspid valve $(13.5 \mathrm{~cm}$ in circumference). There was right ventricular hypertrophy (thickness $1 \mathrm{~cm}$, weight $170 \mathrm{~g}$ ). Just above the junction of the anterior and posterior leaflets of the mitral valve there was a thrombus $0.5 \mathrm{~cm}$ in diameter. The left ventricular myocardium was hypertrophied (thickness $2 \mathrm{~cm}$, weight 300 $\mathrm{g}$ ), with a focus of fibrosis on the anteroseptal wall. The prosthetic valve was in place and obscured in its superior aspect by red friable material (fig 1). Histological examina- 


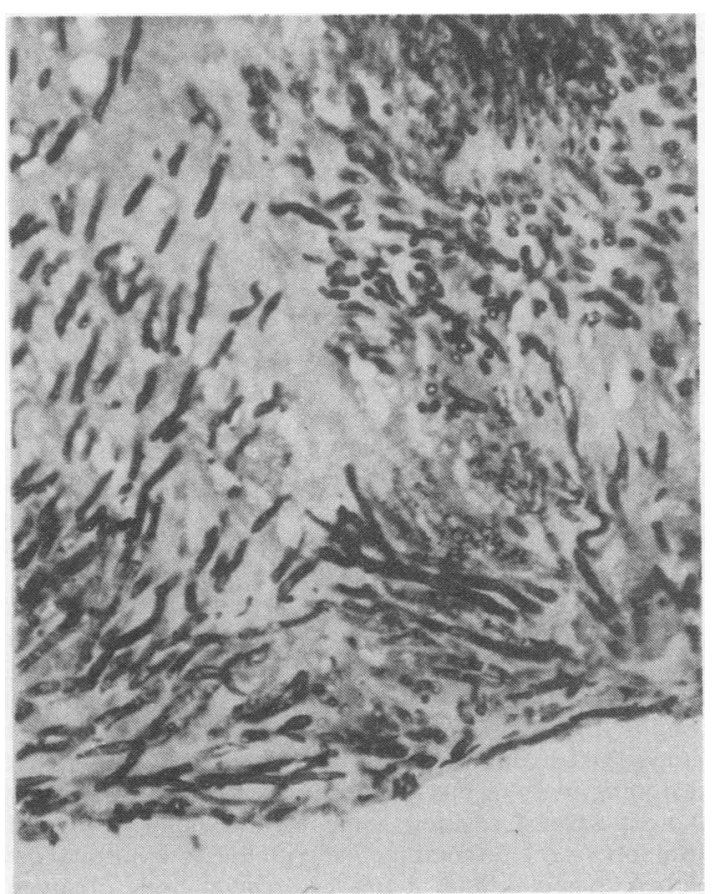

Fig 2 Fungal hyphae taken from the aortic valve; in some areas they are branching and septate. (Methanamine silver, $\times 195$.)

tion of the valve showed destruction of the valve by hyphae compatible with Aspergillus (fig 2). Further sections showed that the left atrial wall was affected. Valve tissue culture yielded a pure growth of Aspergillus niger. The brain was fixed in formal saline but no abscess cavity or haemorrhage was seen. Retrospective histological study of the cerebral arteries showed one vessel to be occluded by Aspergillus niger.

\section{Discussion}

Aspergillus endocarditis has been reported in about 50 patients ${ }^{1-7}$ but has been noted only twice on tissue valves. ${ }^{34}$ The Xenofic valve is a gluteraldehyde treated bovine pericardial tissue valve preserved in sterile $98 \%$ glycerine.

Having noted early fungal invasion of the Xenofic valve and periannular tissue in our patient, we agree with suggestions $\mathrm{s}^{3}$ that a mechanical valve in the supracoronary position with coronary artery grafting should be used in aortic aspergillus endocarditis. This, however, acknowledges our current inability to make an early diagnosis of this condition. Patients may present up to two years after operation with pyrexia of unknown origin and valvular dysfunction. ${ }^{7}$ The diagnosis may be suggested by repeated negative blood cultures. ${ }^{17}$ Unlike in candida endocarditis, antibody titres are rarely raised in aspergillus endocarditis. Echocardiography is too insensitive for specific diagnosis of fungal endocarditis.

Prolonged treatment with amphotericin B, imidazoles, 5 flucytosine, and even immunotherapy, with and without valve excision, produces only a $12 \%$ survival rate in fungal endocarditis in general. ${ }^{1}$ Moreover, McClead and Remington pointed out that immersion of an infected valve in 12.8 $\mu \mathrm{g} / \mathrm{ml}$ amphotericin for one week failed to eradicate candida infection. ${ }^{2}$ We found only three reports of survivors in about 50 patients with aspergillus endocarditis. ${ }^{5610}$ Because of later deaths from recurrence it has been suggested that five and 10 year remission rates should replace the term "cure" in fungal endocarditis.

Our patient had no obvious preoperative source of fungus infection and an uneventful operation. No fungi were grown from the skin ulcer. Later cultures of the preservative and a sample of pericardium of the specific valve used (kept by the manufacturers for reference) were negative for Aspergillus.

Although the infection may have arisen in the operating theatre, about 800 valves have been inserted in our theatres over the past five years without any other case of aspergillus endocarditis being identified.

Diagnosis of this case was made only at necropsy and the findings imply that we must improve diagnostic techniques if we are to lower the mortality of this condition.

\section{References}

${ }^{1}$ Rubenstein E, Noriega ER, Simberkoff MS, Holzman R, Rahal JJ jun. Fungal endocarditis. Analysis of 24 cases and review of the literature. Medicine 1975;54:331-4.

${ }^{2}$ Kammer RB, Utz JP. Aspergillus species endocarditis: the new face of a not so rare disease. Am J Med 1974;56:506.

${ }^{3}$ Drexler L, Rytel M, Keelan M, Bonchek LI, Olinger GN. Aspergillus terreus infective endocarditis on a porcine heterograft valve. J Thorac Cardiovasc Surg 1980;79: 269-74.

${ }^{4}$ Doshi R. Aspergillus fumigatus endocarditis of an aortic homograft with aneurysm of ascending aorta. J Pathol 1971;103:263-5.

${ }^{5}$ Lawrence T, Shockman AT, MacVaugh H. III. Aspergillus infection of prosthetic aortic valve. Chest 1971;60: 406-14.

${ }^{6}$ Carrizosa J, Levison ME, Lawrence T, Kaye D. Cure of Aspergillus ustus endocarditis on a prosthetic valve. Arch Intern Med 1974;133:486-90.

${ }^{7}$ Petheran IS, Seal RME. Aspergillus prosthetic valve endocarditis. Thorax 1976;31:380-90.

${ }^{8}$ Danielson GK, Titus JL, Dushane JE. Successful treatment of aortic valve endocarditis and aortic root abscess by insertion of prosthetic valve in ascending aorta and placement of bypass grafts to coronary arteries. J Thorac Cardiovasc Surg 1974;67:443-9.

' McCleod R, Remington JS. In: Rahimtoola SH, ed. infective endocarditis, New York: Grune and Stratton, 1978:211-90.

${ }^{10}$ Hairston P, Lee WH jun. Management of infected prosthetic heart valve. Ann Thorac Surg 1970;9:229. 